\title{
A sócio-história santista e sua relação com a variação "tu" e "você" nos pronomes de tratamento
}

DOI: http://dx.doi.org/10.21165/el.v49i1.2456

\section{Victor Carreão ${ }^{1}$}

\section{Resumo}

O uso do pronome "tu", na cidade de Santos/SP, destoa do restante do território paulista (MODESTO, 2006). O contato entre imigrantes portugueses e brasileiros, na virada do século XIX para o XX (FRUTUOSO, 2004), é uma possível causa deste fenômeno. A literatura sobre Contato Linguístico guiou o percurso de pesquisa, que destaca como principais fatores sócio-históricos da preservação da forma "tu": (i) Ravindranath (2015) e a demografia e as práticas sociais da comunidade, como a expansão urbana e a concentração de trabalhadores imigrantes no centro santista (MELLO, 2007); (ii) Dodsworth (2017) e a posição do indivíduo na comunidade, como os movimentos operários que integraram a comunidade de Santos (MARAM, 1979); (iii) Britain (2013) e o espaço geográfico e a mobilidade, como as reformas sanitárias e a transformação do espaço santista (MELLO, 2007). Esses fatores convergem para um cenário "solidário" em Santos, favorecendo a forma "tu".

Palavras-chave: linguística histórica; Santos; pronomes de tratamento; contato linguístico; solidariedade.

1 Universidade Estadual de Campinas (UNICAMP), Campinas, São Paulo, Brasil; vcarreao@yahoo.com.br; http://orcid.org/0000-0002-0866-1749 


\title{
The sociohistory from Santos and its relation to the variation of " $\mathrm{tu}$ " and "você" in the pronominal treatment
}

\begin{abstract}
The use of the pronoun "tu" in the city of Santos / SP differs from the rest of the territory of São Paulo (MODESTO, 2006). The contact between Portuguese and Brazilian immigrants, at the turn of the XIX century to the XX (FRUTUOSO, 2004) is a possible cause of this phenomenon. The literature on Linguistic Contact guided the research path, which highlights the main socio-historical factors of preserving the "tu" form: (i) Ravindranath (2015) and the community demography and social practices, such as urban sprawl and concentration of immigrant workers in the Santos center (MELLO, 2007); (ii) Dodsworth (2017) and the position of the individual in the community, such as the workers' movements that integrated the community of Santos (MARAM, 1979); (iii) Britain (2013) and geographic space and mobility, such as sanitary reforms and the transformation of the santista space (MELLO, 2007). These factors converge to a "solidary" scenario in Santos, favoring the "tu" variant.
\end{abstract}

Keywords: historical linguistics; Santos; personal pronouns; linguistic contact; solidarity.

\section{Introdução}

O sistema pronominal do português brasileiro é documentado, em algumas comunidades bem delimitadas de nosso território, como um fenômeno linguístico variável por conta da alternância entre os pronomes "tu" e "você". Em uma visão geral, Furlan (1989) aponta que as cidades litorâneas com altos índices de imigração portuguesa tendem a apresentar tal variação. Costa (2013) detalha essa variação nas capitais da região Norte do país e aponta que o pronome "tu" é mais utilizado em Belém, Manaus e Rio Branco, enquanto em Boa Vista, Macapá e Porto Velho esse pronome é menos observado na fala de seus habitantes. Pensando na região sudeste do Brasil, Paredes Silva (2013) destaca que o alto uso de "tu" é uma característica dos sujeitos na cidade do Rio de Janeiro. Mota (2008) ainda aponta que a forma "tu" é encontrada no estado de Minas Gerais, no município de São João da Ponte e, assim como Furlan (1989), atribui tal cenário à presença de imigrantes portugueses em tempos pretéritos. No estado de São Paulo, na região de Santos, Modesto (2006) registra a variação entre os pronomes "tu" e "você" como uma característica de seus habitantes - destoando do restante do território paulista.

O jornal Novo Milênio - com notícias sobre histórias e memórias de Santos - também registrou esses fenômenos linguísticos. Em uma seção destinada a "nossa língua: a fala dos santistas», Guidi (1985), professor de língua portuguesa e um dos colaboradores do jornal Novo Milênio, aponta que o uso de "tu" em Santos se deve ao grande número de portugueses na cidade - hipótese também delineada em alguns dos estudos aqui citados. 
A presença de imigrantes em Santos foi significante na virada do século XIX para o XX (FRUTUOSO, 2004) - como também veremos a seguir -, contudo, sabemos que a presença de um determinado povo em uma região e de, consequentemente, sua variedade de fala não garante a preferência de uma forma variante linguística. A interação, como nos mostra a literatura sobre Contato Linguístico, é fundamental para que uma ou outra forma ganhe destaque e se espalhe por determinada região. Por conta disso, a hipótese que norteia esse trabalho é a de que o contato entre imigrantes portugueses e os santistas tenha sido a relação que fez com que a variante "tu" ganhasse espaço e se mantivesse até os dias de hoje.

Na virada do século XIX para o XX, Bueno (1967) afirma que as variedades do português do Brasil e de Portugal são vistas de maneira distinta por conta de diferentes fenômenos. Isso implica dizer que a presença portuguesa em Santos é, no fundo, uma questão que firma o contato dialetal entre duas variedades do português: a dos brasileiros que já habitavam a cidade e a dos imigrantes que chegavam. A imigração portuguesa, como sabemos, não é um fato exclusivo de Santos. Como apontado por Miraglia, Almeida e Zanlorenssi (2018), entre os anos de 1884 e 1903, o número mais expressivo de imigrantes entrando no Brasil era o dos italianos. Tal quadro mudaria nos anos seguintes, entre 1904 e 1959, com os portugueses, por vezes, quase representando a metade de todas as entradas imigratórias no país - com cerca de um milhão de portugueses vindo às terras brasileiras entre os anos de 1881 e 1930. No ano de 1929, o total de imigrantes portugueses registrados nos estados do Brasil era de 655.706 indivíduos. Destes, cerca de 90\% estavam em três estados brasileiros (SCOTT, 2001, p. 8): (i) Rio de Janeiro: 272.338 no estado e 31.527 no então Distrito Federal; (ii) São Paulo: 281.418 imigrantes; e (iii) Minas Gerais: 20.050. De acordo com a Secretaria de Estado (1912), o número de imigrantes portugueses nas colônias de imigrantes paulistas era muito baixo.

Partindo do fato de Santos ser uma das principais cidades com alto número de imigrantes portugueses na virada do século XIX para o XX, o objetivo deste trabalho está centrado em verificar como fatores sócio-históricos relacionados à demografia e à dinâmica de trabalho em Santos podem estar associados à permanência da variante "tu" no repertório linguístico dos santistas até hoje. Como analisar dados de fala pretéritos é uma tarefa complexa devido à dificuldade de encontrarmos registros linguísticos, consultaremos Cartas de Chamada, disponíveis no Museu da Imigração de São Paulo, de imigrantes portugueses que já se encontravam em terras brasileiras. Essas cartas eram cartas pessoais que funcionavam como documentos que comprovavam o vínculo familiar de parentes dos imigrantes que já moravam no Brasil.

A literatura sobre contato linguístico embasa esta pesquisa. Embora seja parte do arcabouço teórico deste trabalho, lembramos que a demografia por si só nem sempre é garantia de que formas linguísticas se espalhem pelos falantes de uma comunidade. Primeiro, é preciso verificar como essas formas linguísticas circulam pelo território, ou 
seja, se os falantes circulam ou não pelo território. Caso não circulem, dificilmente as formas entrarão em contato com outros habitantes da cidade. Segundo, a questão que merece destaque é por que alguns traços são espalhados e não outros? Por que "tu" e não outros fenômenos (Noll (2009) aponta que o "s" chiado é observado no repertório linguístico dos santistas, por exemplo)? Por que essas formas, e não outras, ainda é a pergunta de maior impacto em um estudo dessa natureza e, pensando no pronome "tu", uma característica social que faria com que ele fosse mais usado e se espalhasse é a solidariedade citadina. Por essa razão, um estudo da sócio-história santista que mostre como as relações entre os cidadãos se davam é importante de forma a poder reconstruir o lócus do contato linguístico entre os santistas: a forma "tu" era empregada? Por quem? Como circulava? Qual prestígio seus falantes tinham na comunidade? Essas são questões que ajudam a mostrar o caminho que a variável linguística traçou em Santos. Seguiremos com a apresentação da variável linguística e do referencial teórico deste trabalho para, após, explorarmos as características da baixada santista.

\section{Da variável linguística}

Abordar a variação entre "tu" e "você" é discorrer sobre os pronomes de tratamento, que estão intimamente ligados à estrutura social de uma comunidade. O estudo de Cintra (1986, p. 11) sobre as formas de tratamento na língua portuguesa, centrado na linguagem das camadas cultas das grandes cidades de Portugal, objetivou observar "o conjunto de formas que se usam actualmente na alocução ou tratamento directo, não como simples vocativos, mas sim como sujeitos do próprio enunciado". A justificativa para o estudo dessa variável linguística é encontrada em Cintra (1986, p. 36) e é tão atual quanto no tempo em que foi redigida: "[o uso de] tratamentos nominais que assentam em diferenças entre níveis sociais, longe de constituírem um empobrecimento da língua [...] seriam sem dúvida uma útil contribuição linguística para a tão necessária reforma de certos aspectos de estrutura mental e da organização social".

A forma de tratamento estabelece a hierarquia social entre os interlocutores de forma clara. O tratamento é identificado em três formas linguísticas: (i) por tratamentos pronominais: tu, você, vós; (ii) por tratamentos nominais: o senhor, a senhora, o pai, o patrão, etc. (que caracteriza um interlocutor por referência a traços individualizadores); e (iii) por tratamentos verbais: queres, quer, querem (CINTRA, 1986). Por meio destas três formas, podem-se distinguir: formas próprias da intimidade, formas usadas no uso de igual para igual (ou de superior para inferior), e formas de reverência (CINTRA, 1986).

Brown e Gilman (1960, p. 252, tradução nossa²) apontam que, dentro da esfera da semântica, os pronomes variam conforme "a relação objetiva entre os interlocutores". Há uma ligação entre a estrutura social, ideologia de grupo e a semântica do pronome. Para

2 No original: "The objective relationship existing between speaker and addressee". 
verificar o uso dos pronomes de tratamento, Brown e Gilman (1960), em seu estudo sobre "os pronomes de poder e solidariedade", utilizaram peças de teatro antigas (em francês, alemão e italiano) e, para contrastar os dados obtidos com dados mais atuais, aplicaram um questionário a estudantes estrangeiros, em Boston (em 1957), para verificar como os pronomes de tratamento eram utilizados por eles. A ideia dos autores (BROWN; GILMAN, 1960) foi verificar a covariação de "tu" e "vos" (pensando no primeiro como o tratamento a uma única pessoa em um alto grau de intimidade e no segundo como a forma usada para o plural de interlocutores com quem se fala ou para o tratamento com uma única pessoa sem alto grau de intimidade).

A solidariedade semântica, como posta por Brown e Gilman (1960), é o uso de "tu" para intimidade e o de "vos" para formalidade. Esta dimensão dos pronomes de tratamento é diferente da questão do "poder": pessoas são classificadas como "mais/menos poderosas", pois estão em uma situação assimétrica dentro de uma relação - afınal, se uma é mais velha, a outra é mais jovem; se uma é patrão, a outra é empregada; se um é pai, o outro é filho. Mas, em situações em que ambos os interlocutores se encontram na mesma relação (têm a mesma profissão, foram à mesma escola ou são filhos dos mesmos pais (como exemplificado por Brown e Gilman (1960, p. 257)), temos uma situação simétrica. É interessante observar que não é necessariamente a frequência do contato (BROWN; GILMAN, 1960) que leva duas pessoas à criação de uma mesma mentalidade e, consequentemente, intimidade. A explicação para isso reside em diferentes formas de interação que envolvem o eixo "superiores x inferiores" e "igualdade e (não) solidariedade». É possível, por exemplo, que dois «inferiores» estejam em situação de igualdade, mas que não sejam solidários - o que resultaria no emprego de "vos", mesmo sem a questão do "poder" envolvida na estrutura social. Além disso, é preciso considerar a díade também, em que o "papel" de cada indivíduo é levado em consideração (como, em um exemplo de Brown e Gilman (1960, p. 260), a relação entre um "garçom" e um "cliente"). Com base nas peças de teatro analisadas, em filmes contemporâneos e nos questionários aplicados aos alunos estrangeiros, Brown e Gilman (1960, p. 261, tradução nossa ${ }^{3}$ ) registram que houve "o poder é uma relação entre ao menos duas pessoas, e é não recíproco no sentido de que ambas não podem ter poder na mesma área de comportamento. O poder semântico é similarmente não recíproco; o superior diz T [tu] e recebe V [vos]". Dessa maneira, assim que é estabelecido um grau de solidariedade, "tu" se torna o tratamento padrão entre dois interlocutores.

\section{Do contato linguístico}

Diferentes estudos são fundamentados pelo contato linguístico e, em todos, a ideia de dois ou mais grupos de indivíduos em uma mesma comunidade são colocados no centro do

3 No original: "Power is a relationship between at least two persons, and it is nonreciprocal in the sense that both cannot have power in the same area of behavior. The power semantic is similarly nonreciprocal; the superior says $T$ and receives $\mathrm{V}^{\prime \prime}$. 
objeto de estudo, visto por diferentes perspectivas. É possível entender uma comunidade como uma "comunidade de práticas", definida por Eckert e Wenger (2005, p. 583, tradução nossa ${ }^{4}$ ) como "uma negociação coletiva contínua de um regime de competência, que não é estático e tampouco explícito", em que diferentes identidades coexistem e podem ser influenciadas, ou não, umas pelas outras. O que buscamos, aqui, não é aprofundar um conceito ou outro, mas sim, inspirados pelas possibilidades que a interação de grupos em uma mesma comunidade pode gerar, entender quais são os "diferentes pontos de vista" que podem: (a) comprovar o contato entre indivíduos de diferentes variedades de fala; e (b) comprovar que o grau desse contato foi significante em termos quantitativos (a quantidade de interações, simétricas ou assimétricas (nos termos de "poder" de Brown e Gilman (1960)), para que uma forma variante possa se espalhar.

No contexto social, diferentes variáveis podem exercer influência no uso de uma ou outra língua. O primeiro desses fatores é o "domínio de uso", apontado por Ravindranath (2015, p. 247) como os contextos em que é preciso verificar "quem fala qual língua com quem". Como exemplos, cita a família, o parquinho, a escola, a igreja, a literatura, a imprensa, as forças armadas, as cortes e o sistema governamental como domínios de uso em que duas variedades de fala podem ser utilizadas em graus diferentes. 0 tamanho da população de determinada região permite quantificar o uso de uma variedade de língua e verificar o quão útil, valorizada ou usada uma variedade de fala é para os indivíduos que ali estão. Para isso, Ravindranath (2015, p. 248) defende uma "abordagem mais etnográfica, com base em práticas antropológicas, evitando categorias sociais préconcebidas e, ao invés disso, usando categorias regionais que são mais significativas, uma vez que o pesquisador esteja mais familiarizado com a comunidade". Em termos de pesquisas variacionistas, determinada comunidade pode ter uma variável social como "afiliação religiosa" se mostrando mais produtiva para explicar a variação linguística do que variáveis sociais censitárias.

Podemos entender que um falante pode estar mais ou menos associado a determinado tipo de domínio de uso, o que pode implicar em maior ou menor uso de determinada variedade de fala/língua. Assim, analisar a rede social em que os falantes se encontram pode auxiliar a entender melhor o seu comportamento de fala. Pensando no indivíduo dentro de uma comunidade, Dodsworth (2017, p. 342-343) ressalta que é interessante verificar "em quais maneiras a posição de um indivíduo na estrutura de uma comunidade influencia sua adoção de novas 'formas dialetais"'. O papel das identidades individuais é o assunto central da terceira onda da sociolinguística (como posto por Penelope Eckert em muitos de seus trabalhos) e significativo para compreendermos a variação linguística. Por conta da imigração e globalização, verificar a maneira pela qual as identidades locais e globais são estabelecidas é importante para entender a direção que determinadas formas variantes podem tomar em situações de contato linguístico.

4 No original: "A community of practice can be defined as an ongoing collective negotiation of a regime of competence, which is neither static nor fully explicit". 
Já Britain (2013, p. 475, tradução nossa5) destaca a maneira pela qual algumas áreas da linguística lidam com o espaço: "geógrafos dialetais estiveram ocupados quantificando o espaço geométrico, desprovido de seu conteúdo social, enquanto os sóciolinguístas urbanos estudavam suas comunidades de fala com pouca atenção às integrações com estruturas socioespaciais maiores". Dessa maneira, Britain (2013) aponta que os linguistas muitas vezes se preocupam apenas com uma característica do espaço: ou apenas com seus falantes, sem considerar como o espaço e suas redes de mobilidade podem influenciar o comportamento de fala que é relatado, ou apenas com as marcações geográficas e o tipo de variantes linguísticas que podem ser encontradas nos falantes dessa região, como os atlas linguísticos fazem. Assim, é importante considerar o falante incluído no espaço em que vive e como que as redes de mobilidade podem estar associadas à variação/mudança linguística que é observada em suas falas.

Com essas três perspectivas em mente - a demografia, o indivíduo dentro da comunidade e o espaço/mobilidade -, é interessante verificar como era a variedade de fala dos imigrantes portugueses na época para que essas características sociais possam ser verificadas em Santos.

\section{Dos dados levantados}

De forma a verificar a variedade de fala dos imigrantes portugueses que vieram para o Brasil na virada do século XIX para o XX, 130 cartas, disponíveis no Acervo Digital do Museu da Imigração do Estado de São Paulo (2019), foram consultadas e transcritas. 0 intuito desse levantamento de dados foi verificar como a variedade de fala dos imigrantes portugueses, no estado de São Paulo, comportava-se em relação aos pronomes de tratamento. Assim, temos nas cartas as seguintes ocorrências para os pronomes de tratamento:

Tabela 1. Número de ocorrências de pronomes pessoais nas cartas

\begin{tabular}{c|c}
\hline Pronome Sujeito & $\mathbf{N}^{\circ}$ Ocorrências \\
\hline $\begin{array}{c}\text { Terceira pessoa } \\
\text { você, mãe, pai, senhor(a) }\end{array}$ & $425(84 \%)$ \\
\hline Tu & $80(16 \%)$ \\
\hline TOTAL & 505 \\
\hline
\end{tabular}

Fonte: Elaboração própria

5 No original: "Dialect geographers were busy quantifying geometric space, devoid of its social content, whilst urban sociolinguists studied their speech communities with little regard for their integration into a larger socio-spatial framework". 
Os dados levantados mostram que pronomes de tratamento relacionados a sujeitos de terceira pessoa (como o uso de "você", "pai", "mãe", "senhor(a)") predomina nas cartas analisadas. Pensando na hierarquia entre os interlocutores (ver BROWN; GILMAN, 1960), a variável social a que nos propomos a observar neste trabalho, podemos notar como o tratamento foi realizado entre interlocutores mediante a relação de poder entre eles (por exemplo, pai e filho, mãe e filha, entre outras possibilidades). O número de cartas para cada tipo de hierarquia segue abaixo:

Tabela 2. Número de cartas pessoais de imigrantes portugueses conforme suas hierarquias

\begin{tabular}{c|c}
\hline Hierarquia & Número \\
\hline Alta & 1 \\
\hline Baixa & 99 \\
\hline Igual & 30 \\
\hline TOTAL & 130 \\
\hline
\end{tabular}

Fonte: Elaboração própria

Das cartas de hierarquia "igual" (entre amigos ou irmãos, por exemplo), 17 (56\%) utilizam o pronome "tu". Das de hierarquia "baixa" (de um filho para os pais, por exemplo), apenas 10 (10\%) apresentam o pronome "tu". A única carta de hierarquia "alta" (de um pai para um filho, por exemplo) utiliza o pronome "você". As ocorrências de "tu" não parecem condicionadas ao sexo/gênero do emissor ou do receptor, mas sim à hierarquia entre os dois interlocutores:

Tabela 3. Número de ocorrências de sujeitos de "terceira pessoa" e "tu" a hierarquia das cartas

\begin{tabular}{c|c|c}
\hline Hierarquia/Tratamento & Terceira pessoa & Tu \\
\hline Baixa & $367(86 \%)$ & $22(27 \%)$ \\
\hline Igual & $58(14 \%)$ & $58(73 \%)$ \\
\hline TOTAL & 425 & 80 \\
\hline
\end{tabular}

Fonte: Elaboração própria

A proporção do uso de "tu" e de sujeitos de "terceira pessoa" é inversa conforme a hierarquia entre os interlocutores das cartas: "tu" é mais usado em condições simétricas de poder, enquanto os sujeitos de "terceira pessoa" são mais registrados em situações 
assimétricas. É possível afirmar que, para que a forma "tu" tenha sobrevivido até os dias de hoje, as relações sociais dentro da comunidade em que isso ainda pode ser observado eram mais próximas da igualdade/solidariedade do que em uma hierarquia de poder. Esse é um ponto de partida ao tomarmos a imigração portuguesa como o ponto catalisador para essa forma linguística na cidade de Santos: o grande número de portugueses em Santos estava inserido em uma comunidade "solidária" - e por "solidária" entenderemos "união" e "contato constante".

Em Santos/SP, Modesto (2006) ressalta que as formas "tu" e "você" são utilizadas com verbos conjugados na terceira pessoa do singular, não havendo flexão de segunda pessoa para as ocorrências de "tu". Modesto (2006) também entrevistou alunos de escolas santistas e verificou que existe estigma no uso da forma "tu", sendo ela mais rude, informal e incorreta na opinião dos entrevistados - que também consideram essa forma mais "íntima" do que a forma "você". Em outro estudo, analisando as formas de tratamento em uma peça de teatro em São Vicente, Modesto (2005, p. 15) afirma que "a forma tu é presença viva e marcante na região [da baixada santista], usada por jovens em situação de um registro informal" e destaca: "não verificamos, por exemplo, diferenças de uso quanto às questões exclusivas de hierarquia social e poder e solidariedade, mas sim em termos de relações pragmáticas que se estabelecem durante o evento comunicativo" (MODESTO, 2006, p. 120). Um olhar sobre a hierarquia social na época da expansão da cidade é interessante para buscar entender essa variação no tratamento santista atual.

\section{A sócio-história santista e o espalhamento de formas linguísticas}

O primeiro forte indício de contato entre imigrantes portugueses e brasileiros em Santos é a demografia. Esse fator é apontado por Ravindranath (2015) como o principal para um estudo de contato linguístico. De forma resumida, esse contato entre os dois grupos em Santos pode ser observado na cronologia a seguir:

Nos anos que margeiam a passagem do século XIX para o XX, Santos sofreu grandes transformações, ligadas à revolução técnica e ao desenvolvimento do capitalismo: inauguração da ferrovia (1867); início da modernização do porto (1890); o saneamento, vencendo as terríveis epidemias; a urbanização com o alargamento da cidade, dando-lhe uma nova configuração.

A população santista aumenta como um reflexo do próprio crescimento econômico da cidade. Assim, nos anos de 1886, era de 15.605 habitantes; cresce vertiginosamente em 1900 para 50.389. O Censo de 1913 revela uma população de 88.967 habitantes dos quais 39.802 são imigrantes (44\% da população); destes, 23.055 são portugueses, seguindo-se 8.343 espanhóis e 3.554 italianos. 
Já em 1892, há registro da chegada em Santos de 500 lusos com experiência na construção de portos. É, sobretudo, em fins do século XIX até a década de 1930 que Santos atrai esse maior número de portugueses.

Os censos gerais de 1920 e 1940 ainda mostram a forte presença lusitana na população santista e os lusos continuam sendo a corrente imigratória mais importante da cidade. Santos torna-se uma cidade portuguesa, considerando-se também os descendentes. (PEREIRA; FRUTUOSO, 2007, p. 282-283).

Os acontecimentos acima ajudam a entender como se deu a expansão da cidade e como isso agrupou diferentes grupos de pessoas no território. O crescimento urbano santista é observado no mapa abaixo, que também auxilia a entender a concentração de diferentes grupos na virada do século XIX para o XX:

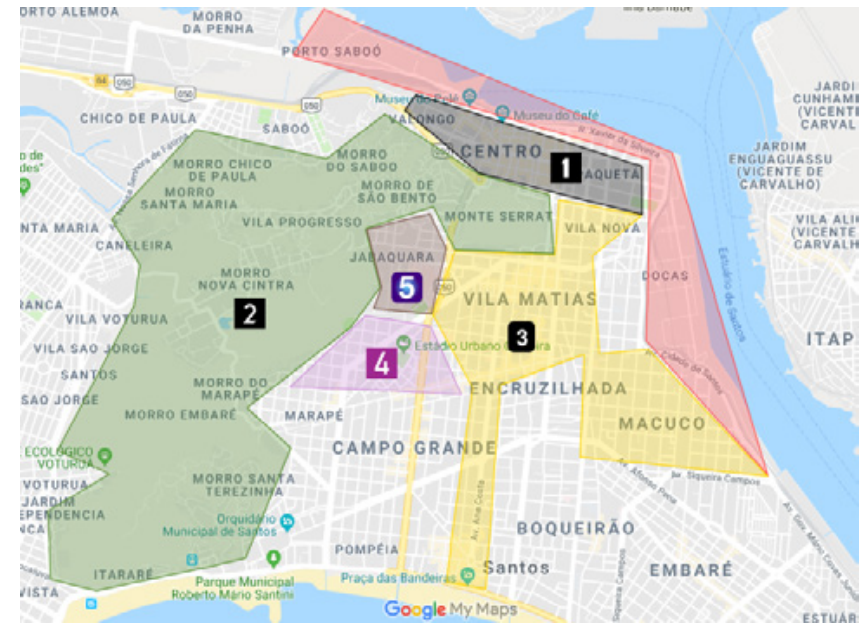

Figura 1. Expansão santista na virada do século XIX para o XX

Fonte: Adaptado de Novo Milênio (2019)

A região vermelha, no mapa acima, corresponde à área sobre controle da Companhia das Docas. As obras lideradas pela Docas imprimiram diferentes arranjos urbanos sobre a cidade: as regiões se transformaram e seus moradores foram deslocados. A área de número 1 representa o Centro da cidade. A região verde (número 2) corresponde aos morros santistas. As numerações das regiões mostram a ordem cronológica de ocupação do território. Sobre os bairros de Santos no início do século $X X$, representados na área amarela (número 3), Carreira (2018) aponta que a Vila Mathias e a Vila Macuco foram lar de trabalhadores portuários. Nos anos seguintes, novos bairros eram levantados seguindo o traçado de ruas e avenidas, como a Vila Belmiro (entre 1910 e 1915) Campo Grande (a partir de 1915) e Marapé (no final da década de 1920) - assinaladas na figura acima com o número 4. Já o bairro de Jabaquara (número 5) formou-se na década de 20. 
Aqui é interessante destacar o fato de que a expansão santista para além do Centro começou por volta dos anos 1900, o que mostra que os imigrantes e trabalhadores do porto viviam em uma área com pouco menos de um quilômetro quadrado - e com cerca de 10 pessoas por habitação (GITAHY, 1992). Quando o estabelecimento dos habitantes de Santos passou a ocorrer em outros lugares, os morros foram o primeiro lugar em que novas concentrações de pessoas foram observadas, enquanto a elite brasileira santista da época se deslocava para a orla sul da praia (MELLO, 2008).

O principal tipo de construção encontrado nos morros eram os chalés, construção típica dos imigrantes portugueses e espanhóis. Silva e Gitahy (1996), ao discorrer sobre a construção civil em Santos, mostram que a "febre das construções" mudou o cenário urbano da cidade: em 1872, havia 1407 prédios em Santos contra 10.578 no ano de 1913 - período em que a construção por encomenda predominava, deixada a cargo de vários empreiteiros e mestres de obras. Há uma estimativa de que, em 1913, existissem 1697 casebres/chalés em Santos (SANTOS apud SILVA; GITAHY, 1996). Dessa maneira, é possível verificar que os dois grupos, imigrantes e brasileiros, estiveram em contato constante na virada do século XIX para o XX e que a presença portuguesa também estava impressa na arquitetura da cidade, não se tratando de um grupo marginalizado ou de pouca presença no município.

A disposição dos bairros e seus moradores são informações relacionadas ao que Britain (2013) aponta como mobilidade dentro de um território/comunidade. Não só o desenvolvimento de linhas de bondes conectou a cidade, mas, também, a dinâmica de trabalho e consumo dentro dela - fato que pode ser atestado conforme a oferta de produtos e serviços em Santos. Os anúncios de diversos produtos comercializados pelas casas de comércio - principalmente os produtos alimentícios - apontam o que é, para Pedro (2010, p. 90), uma "popularização do consumo", incentivando a movimentação pelas ruas da cidade - sem a dispersão da população pelo território.

Pensando no papel do indivíduo dentro da comunidade (DODSWORTH, 2017), algumas informações sobre os imigrantes portugueses são de suma importância para nossa análise. Como apontado por Pereira (2013), os imigrantes portugueses muitas vezes casavam-se entre si - esse tipo de interação também refletiu, como veremos a seguir, na sucessão de determinadas funções no porto, como a dos estivadores (que só poderiam cumprir a função caso fossem descendentes de portugueses).

Pedro (2010) também destaca que muitos imigrantes portugueses chegavam a Santos e logravam buscar empregos no comércio - como caixeiros ou comerciantes. Alguns conseguiam alcançar o sucesso de seus estabelecimentos, passando a negociantes do alto comércio com "casas comissárias, exportadoras de café e importadoras". É importante destacar que a maior parte dos imigrantes trabalhava nos serviços portuários, mas, "de um modo geral, os imigrantes trabalhavam em todas as atividades urbanas" (MELLO, 2008, p. 25). 
Pereira e Frutuoso (2007, p. 284) tecem comentários acerca do trabalho realizado pelos imigrantes na cidade de Santos, litoral do estado de São Paulo: "No censo de 1913 os portugueses são operários braçais, trabalhando no porto e na ferrovia (10.118), em atividades industriais (976). Em setores mais abonados são: 119 capitalistas e proprietários, 920 negociantes (nos ramos de secos e molhados etc.)". O percurso, até aqui, mostra o estabelecimento dos portugueses em Santos e sua presença por todo o território santista, bem como o exercício profissional em praticamente todas as atividades profissionais da cidade. Mas o caráter de união enquanto comunidade ainda parece questionável: a demografia, por si só, e a circulação dentro da cidade não são garantia de coesão - o que poderia, possivelmente, refletir na adoção de uma forma linguística deste grupo. A chave para esse entendimento nos parece estar na relação de trabalho santista:

Santos também concentrou um grande número de imigrantes lusos, que trabalhavam na construção do porto, nos armazéns de café, nas docas e em atividades variadas: carroceiros, pedreiros, estivadores, ensacadores, entre outras. A região converteu-se num grande centro de agitação operária e recebeu o codinome "Barcelona do Brasil". Os sindicatos e associações santistas eram dominados pela liderança de imigrantes portugueses. (PASCAL, 2008, p. 4, grifos nossos).

Foi em Santos que foi deflagrada a primeira greve geral do país, bem como pode ser observado o surgimento dos primeiros movimentos sociais e sindicais brasileiros; como aponta Gitahy (1992, p. 59), "a greve de 1891, a primeira greve geral de nível local no País, foi significativa para o nascimento do movimento operário santista". Parte desse processo foi motivada pela companhia que operava nas obras e gerenciamento do porto: a Docas - empresa que teve grande importância no desenvolvimento da cidade e de sua comunidade. Gitahy (1992, p. 33) destaca que "a construção e o monopólio do Porto pela Cia. Docas geram uma reorganização do trabalho e do próprio espaço da cidade empreendida sob o signo da disciplina e da eficiência capitalistas".

Carreira (2018) também ressalta que, no fim do século XIX, a dinâmica de trabalho santista girava ao redor do porto - em especial, as atividades da empresa Docas, também conhecida como "polvo" por ter atuação em todos os segmentos profissionais da cidade (como também apontado por Gitahy (1983)). Para Carreira (2018, p. 32), "os tentáculos da Companhia Docas e os canteiros de obras da Companhia Construtora de Santos, direta e indiretamente, se espraiavam pelos quatro cantos da cidade", principalmente pela influência política de suas diretorias - que tiveram participação, inclusive, na disseminação do futebol na cidade. Sendo a Docas tão influente, a organização e junção dos trabalhadores em seus movimentos operários foi uma maneira de responder à altura como um grande grupo e comunidade. 
A união - e solidariedade - da comunidade santista é caracterizada por dois fatores: primeiro, o fato de, praticamente, toda atividade de trabalho na cidade estar associada ao porto e ao comércio (a cadeia logística do comércio do café, por exemplo, envolvia tanto os trabalhadores da ferrovia como os do porto, bem como os carroceiros, ensacadores e estivadores no processo de carga e descarga, bem como aqueles destinados à compra e venda - o que inclui até mesmo trabalhadores de tecelagens que costuravam os sacos utilizados no manuseio do café). A maioria desses trabalhadores era de origem portuguesa; segundo, o monopólio da empresa Docas sobre a cidade, não se limitando apenas ao porto santista, mas também presente nas reformas sanitárias, urbanismo e política da cidade. A única forma de lutar contra esse monopólio foi a criação dos movimentos sociais e sindicatos, cuja maioria era chefiada por imigrantes portugueses. Gitahy (1992, p. 138) também aponta que "a maior parte dos santistas simpatizava com os grevistas", o que nos leva a crer que a solidariedade não se restringia apenas aos movimentos sociais, mas também ao restante da sociedade santista (que era igualmente afetada).

A presença portuguesa também refletiu nas relações de trabalho da cidade. Além de serem quase todos os mestres e contramestres da estiva, havia a garantia de emprego aos filhos dos estivadores - em um sistema que garante emprego na área para a descendência dos trabalhadores -, sendo uma característica que perdura até o fim da década de 1950 (SARTI, 1981, p. 36). Em relação a isso, Sarti (1981, p. 45) destaca, por exemplo, o "Projeto de Nacionalização da Estiva", assinado por Getúlio Vargas, em que é estipulado "o limite máximo de 1/3 de operários estrangeiros com direito a matricularemse na Capitania dos Portos" a fim de evitar as agitações políticas trazidas por aqueles que não eram brasileiros. As relações de trabalho são, dessa maneira, os caminhos para explorar o contato linguístico entre as duas variedades do português em Santos.

\section{Considerações finais}

A grande demografia de imigrantes portugueses, o pequeno espaço em que residiam e a influência dentro dos movimentos operários - que deram a Santos a unidade enquanto uma comunidade - fazem com que a circulação de formas linguísticas seja possível, pois a circulação e influência dos imigrantes portugueses era grande. Em um paralelo, sem a intenção de nos aprofundarmos no assunto, podemos pensar nas ocorrências de "tu" na cidade do Rio de Janeiro (PAREDES SILVA, 2003) e sua possível relação com os imigrantes portugueses, em tempo ainda pretérito aos movimentos sociais santistas: a vinda da família real para o Brasil, em 1808, em que a presença portuguesa não trazia apenas uma parcela considerável de imigrantes (pensando na demografia), mas que também contava com um grupo de prestígio dentro do império. É claro que a maneira pela qual a estrutura social carioca se estabeleceu difere da santista. Ainda assim, arriscamos dizer que a demografia deve apresentar influência dentro de uma comunidade, característica que será colocada por Eckert e Wenger (2005) como "legitimidade". 
Podemos observar os movimentos operários, as nacionalidades e até mesmo o lazer como fatores de solidariedade que uniram os moradores de Santos na virada do século XIX para o XX. Carreira (2018, p. 30-31) resume dois importantes deslocamentos populacionais dentro da cidade de Santos: em um primeiro momento, os imigrantes e operários se situam no centro da cidade, na virada do século XX para o XIX, por conta do trabalho no porto de Santos, o que faz com que a elite santista desça para o litoral da cidade; em outro momento, na década de 1920, os operários são "empurrados" do centro para os morros (como o bairro do Macuco) e para o leste santista em um processo de reurbanização com "habitações destinadas à classe trabalhadora". Com os brasileiros fora do Centro e das áreas adjacentes ao porto, a forma "tu" encontraria maior espaço para circular - principalmente pelo fato de termos uma comunidade em que todos estariam em "nível de igualdade" hierárquica por serem todos operários. É claro que há distinção dentro da hierarquia do porto e dos movimentos sociais (SARTI, 1981), mas o regime de contratação de "exército reserva", em que não há vínculo trabalhista com a Docas, faz com que essa hierarquia passageira possa ser questionada.

É interessante verificar, também, que a maioria dos imigrantes não tinha planos de fixar residência no Brasil, pois não chegaram a requisitar a nacionalidade brasileira (ver GITAHY, 1992), buscando formas de enriquecer. Essa mobilidade social está ligada à forma de tratamento, como aponta Modesto (2006, p. 14):

Há uma grande pressão da solidariedade sobre o poder, e os grupos fechados e altamente hierarquizados do passado transformaram-se em grupos mais abertos, cuja hierarquia torna-se mais complexa. A mobilidade social agora se tornou uma constante, ficando, portanto, difícil estabelecer noções fixas sobre as dimensões de poder e solidariedade

Como apontam Brown e Gilman (1960, p. 265, tradução nossa), "a solidariedade semântica recíproca tem crescido com a mobilidade social e ideologias igualitárias". As características de união trazidas pelos movimentos operários em Santos se estenderam a toda a cidade, tendo origem em um grupo predominantemente de imigrantes - e também liderados por eles - e se espalhando a outros trabalhadores que, brasileiros ou não, foram beneficiados por suas lutas e solidários a elas.

É possível, sumarizando, considerar a sociedade santista da virada do século XIX para o XX como uma grande comunidade de característica operária; e isso aproxima esse grupo do conceito de Comunidades de Práticas: de acordo com Eckert e Wenger (2005, p. 582, tradução nossa6), "comunidades de prática são um bom local para estudar como o poder é organizado e exercido em práticas linguísticas do dia-a-dia". Eckert e Wenger

6 No original: "Communities of practice are a good locus for studying how power is organized and exercised in day-to-day linguistic practice". 
(2005) apontam algumas questões que devem ser consideradas ao trabalharmos com hierarquias ou cadeias de poder em comunidades. Um desses pontos é o fato de que as hierarquias são comumente consideradas como estruturas lineares, o que nos leva a crer que o poder reside em determinadas posições desse fluxograma. Por fim, como ressaltam Eckert e Wenger (2005, p. 583), "prática" e "atividade" não são a mesma coisa; em outras palavras, não podemos considerar um indivíduo que realiza certas atividades como automaticamente membro de uma comunidade caracterizada por realizar essa determinada atividade.

Uma "prática" é uma "maneira de realizar as coisas, fundada em e compartilhada por uma comunidade" (ECKERT; WENGER, 2005, p. 583, tradução nossa7). A distinção entre esses dois pontos é necessária para melhor entender o que é "legitimidade" dentro de uma hierarquia: desenvolver uma atividade caracterizada como a prática de uma comunidade é diferente de estar em certo nível dessa comunidade que decide o que deve fazer parte de suas atividades ou não; isso é legitimidade (ECKERT; WENGER, 2005, p. 583). No caso dos movimentos operários santistas, os imigrantes portugueses apresentavam essa legitimidade, assim como nas funções desempenhadas no porto, ferrovias, comércio e outras atividades. Esses são os primeiros passos de uma investigação que busca usar fontes sócio-históricas para traçar a causa da manutenção do pronome "tu" na cidade de Santos e nos parece ser o fator social que melhor sustenta esses processos linguísticos na cidade.

\section{REFERÊNCIAS}

BRITAIN, D. Space, diffusion and mobility. In: CHAMBERS, J. K.; SCHILLING, N. The Handbook of Language Variation and Change. 2nd ed. Malden, MA: Wiley-Blackwell, 2013. p. $72-500$.

BROWN, R.; GILMAN, A. The Pronouns of Power and Solidarity. In: SEBEOK, T. A. (org.). Style in Language. MIT Press, 1960. p. 253-276.

BUENO, F. S. A formação histórica da Língua Portuguesa. São Paulo: Edição Saraiva, 1967.

CARREIRA, A. L. R. A "Religião Leiga da Classe Operária" e os sentidos da cidade: urbanização, trabalho e futebol na cidade de Santos (1892-1920). Recorde, Rio de Janeiro, v. 11, n. 2, p. 1-36, jul./dez. 2018.

CINTRA, L. F. L. Sobre formas de tratamento na língua portuguesa. 2. ed. Lisboa: Livros Horizonte, 1986.

7 No original: "Is a way of doing things, as grounded in and shared by a community". 
COSTA, L. B. Variação dos pronomes "tu"/"você" nas capitais do norte. 2013. Dissertação (Mestrado em Letras) - Instituto de Letras e Comunicação, Universidade Federal do Pará, Belém, 2013.

DODSWORTH, R. Migration and dialect contact. Annual Review of Linguistics 3, p. 331-346, 2017.

ECKERT, P.; WENGER, E. Communities of practice in sociolinguistics: what is the role of power in sociolinguistic variation? Journal of Sociolinguistics, n. 9/4, p. 582-589, 2005.

FRUTUOSO, M. S. G. O café e a imigração em Santos. Histórias e Lendas de Santos. 2004. Disponível em: http://www.novomilenio.inf.br/santos/h0219.htm\#Autora. Acesso em: 27 dez. 2018.

FURLAN, O. A. Influência Açoriana no Português do Brasil em Santa Catarina. Florianópolis: UFSC, 1989.

GITAHY, M. L. C. Os trabalhadores do Porto de Santos (1889-1910). 1983. Dissertação (Mestrado em História) - Instituto de Filosofia e Ciências Humanas, Universidade Estadual de Campinas, Campinas, 1983.

GITAHY, M. L. C. Ventos do mar: trabalhadores do porto, movimento operário e cultura urbana. São Paulo: Editora da Universidade Estadual Paulista, 1992.

GUIDI, S. Nossa língua: a fala dos santistas. 4 nov. 1985. Disponível em: http://www. novomilenio.inf.br/santos/h0089.htm. Acesso em: 07 abr. 2019.

MARAM, S. L. Anarquistas, Imigrantes e o Movimento Operário Brasileiro. Rio de Janeiro: Paz e Terra, 1979.

MELLO, G. A modernização de Santos no século XIX: mudanças espaciais e da sociabilidade urbana no centro velho. Cadernos CERU, v. 18, p. 107-131, 2007.

MELLO, G. Expansão e estrutura urbana de Santos (SP): aspectos da periferização, da deterioração, da intervenção urbana, da verticalização e da sociabilidade. 2008. Dissertação (Mestrado em Sociologia) - Faculdade de Filosofia, Letras e Ciências Humanas, Universidade de São Paulo, São Paulo, 2008. 
MIRAGLIA, P.; ALMEIDA, R.; ZANLORENSSI, G. O fluxo de imigração ao Brasil desde a chegada dos portugueses. NEXO, Gráfico, 11 jun. 2018. Disponível em: https://www. nexojornal.com.br/grafico/2018/06/11/0-fluxo-de-imigração-ao-Brasil-desde-achegada-dos-portugueses. Acesso em: 19 nov. 2018.

MODESTO, A. T. T. Formas de tratamento no português brasileiro: a alternância tu/você na cidade de Santos - SP. 2006. Dissertação (Mestrado em Filologia e Língua Portuguesa) - Faculdade de Filosofia, Letras e Ciências Humanas, Universidade de São Paulo, São Paulo, 2006.

MODESTO, A. T. T. Notícias de estudos realizados sobre as formas de tratamento no português brasileiro. Letra Magna, v. 2, n. 2, p. 1-9, 2005.

MOTA, M. A. A variação dos pronomes 'tu' e 'você' no português oral de São João da Ponte (MG). 2008. Dissertação (Mestrado em Estudos Linguísticos) - Faculdade de Letras, Universidade Federal de Minas Gerais, Belo Horizonte, 2008.

MUSEU DA IMIGRAÇÃO. Acervo Digital. Disponível em: http://www.inci.org.br/ acervodigital/. Acesso em: 23 abr. 2019.

NOLL, V. O mito da origem portuguesa do chiamento carioca. In: RIBEIRO, S. S. C.; COSTA, S. B. B.; CARDOSO, S. A. M. (org.). Dos sons às palavras: nas trilhas da Língua Portuguesa. Salvador: EDUFBA, 2009. p. 306-319.

NOVO MILÊNIO. Planta e projetos de Santos, 1910. Disponível em: http://www.novomilenio. inf.br/santos/mapa27.htm. Acesso em: 04 abr. 2019.

PASCAL, M. A. M. Imigrantes portugueses: anarquistas e comunistas sob o olhar do DEOPS. Anais do XIX Encontro Regional de História: Poder, Violência e Exclusão. ANPUH/ SP-USP. São Paulo, 2008.

PEDRO, C. M. F. Casas importadoras de Santos e seus agentes: comércio e cultura material (1870-1900). 2010. Dissertação (Mestrado em História Social) - Faculdade de Filosofia, Letras e Ciências Humanas, Universidade de São Paulo, São Paulo, 2010.

PEREIRA, M. A. F. Casamentos de portugueses no arquivo da Paróquia Coração de Maria em Santos, no bairro de Vila Mathias (1915-1920). In: ARRUDA, J. J.; FERLINI, V. L. A.; MASTOS, M. I. S.; SOUSA, F. De Colonos a Imigrantes. Centro de Estudos da População, Economia e Sociedade: Porto, 2013. 
PAREDES SILVA, V. L. Motivações funcionais no uso do sujeito pronominal: uma análise em tempo real. In: PAIVA, M. da C. de; DUARTE, M. E. L. (org.). Mudança Lingüística em Tempo Real. Rio de Janeiro: Contra Capa Livraria, 2003.

PEREIRA, M. A. F.; FRUTUOSO, M. S. Fontes para o estudo da presença portuguesa em Santos. In: SOUSA, F.; MARTINS, I. L.; PEREIRA, C. M. (org.). A emigração portuguesa para o Brasil. Santa Maria da Feira: Rainho \& Neves, 2007.

RAVINDRANATH, M. Sociolinguistic variation and language contact. Language and Linguistics Compass, v. 9, n. 6, p. 243-255, 2015.

SARTI, I. Porto Vermelho. Rio de Janeiro: Paz e Terra, 1981.

SCOTT, A. S. V. As duas faces da imigração portuguesa para o Brasil (décadas de 18201930). História Econômica, 2001. Disponível em: http://www.aehe.es/wp-content/ uploads/2001/10/volpiscott.pdf. Acesso em: 20 nov. 2018.

SECRETARIA DE ESTADO. Relatorio apresentado ao Dr. M. J. de Albuquerque Lins, presidente do estado, pelo Dr. Antonio de Padua Salles, secretario da agricultura: annos de 1910 e 1911. São Paulo: Rothschild \& Cia, 1912.

SILVA, F. T. S.; GITAHY, M. L. C. O movimento operário da construção civil santista durante a Primeira Guerra Mundial (1914-1918). História Social, n. 3, p. 87-124, 1996. 